\title{
HEDGING CURRENCY RISKS? \\ AN EVALUATION OF SMES \\ IN NORTHERN GERMANY
}

Jan Christoph Neumann ${ }^{1}$

${ }^{1}$ Mendel University in Brno, Czech Republic

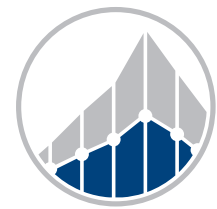

EUROPEAN JOURNAL OF BUSINESS SCIENCE AND TECHNOLOGY

Volume 5 Issue 2

ISSN 2694-7161

www.ejobsat.com

\begin{abstract}
One of the important issues for companies is liquidity from domestic and foreign trade. The market is classically defined by the number of available markets. Globalization and free trade zones set up the foreign market, which becomes increasingly important - even for SMEs. This paper analyzed approx. 60,000 bank transactions with foreign reference of Northern German SMEs by using Chi-square test and correlation analysis. The analysis proofs that an increasing number of foreign transfers increases the number of foreign currency accounts per company. The results also show that despite the existence of currency hedging tools, a significant proportion of SMEs continues to expose themselves to currency risk. The willingness to manage currency risks increases with the increase in value per transaction. Transactions with a value of less than EUR 10,000 are often transferred abroad in EUR instead of in foreign currency.
\end{abstract}

\section{KEY WORDS}

active currency management, hedging instruments, exporters, importers, currency volatility, foreign currency account, forwards, swaps

\section{JEL CODES}

A10, G30, G40

\section{INTRODUCTION}

Managing foreign exchange risk remains a controversial issue, as far as it comes to hedging. With Shakespeare's Hamlet, we can say: "To hedge or not to hedge that is the question." A primary focus of hedging is the reduction of the volatility of earnings and to increase companies' value. FX-exposure is a financial risk that all firms with foreign reference face as part of their ongoing operations. Firms face this risk regardless of whether trading in foreign currencies or not (McCarthy, 2014), as far as foreign goods are purchased, or goods sold 
abroad - regardless of the invoiced currency. Whenever international trading is relevant for a company, an important factor is the volatility of currencies, influencing the profit. Managing exchange rate risks is an integral component in every company's decision whilst exposure to foreign currencies. According to Deltuvaitè et al. (2019), foreign currency positions are mainly influenced by exchange rate fluctuations and economic shocks, while the effects of interest rate shocks or inflation are limited. Following the argumentation of Papaioannou (2006), the importance of the exchange rate risk management arises with the disintegration of the Bretton Woods system as well as the end of the peg of U.S. dollars to gold in 1973.

While many empirical studies focus on the hedging activity of larger companies, only a few publications provide evidence on the use of hedging within small and medium sized enterprises (SMEs). ${ }^{1}$ Within the scope of Malindretos and Tsanacas (1995) the smaller-sized companies are mostly forgotten or overlooked in studies within the FX-market, due to the dominance of MNEs in foreign business (Kula, 2012). Besides, only a few studies in the existing literature are reflecting the use of hedging in SMEs, while the research mostly concerns multinational firms. Every firm is subject to financial distress if it has frequent cash shortages and only a few revenue streams. This implies the problem of SMEs: the likelihood to experience financial distress is much higher compared to MNEs, due to the limited availability of assets in most cases. If a firm faces insolvency problems, it usually liquidates assets to settle debts. Ordinarily SMEs are having less assets to sell and are more likely to default (Quintiliani, 2018). Another study of FX-risks within the range of SMEs already argues that the probability of financial distress for SMEs is characterized as high, due to their typical capital structure (Keasey and Watson, 1993; Andrade and Kaplan, 1998; Frank and Goyal, 2009; Bhaird and Lucey, 2010). They examined the qualitative and quantitative elements of financial distress costs of SMEs by using a company's sample of two EU countries. On the one hand they found out, that German SMEs are subsidized by governmental programs and mainly financed by one local bank or "Mezzanine Kapital". On the other hand, they found out, that hedging is rarely used in SMEs, as they have a low ex ante perception of foreign exchange risk or, in the best case, only hedge individual transactions. That is why it makes no sense to hedge selectively, as any open currency position poses an open risk. Brown et al. (2006) investigated in their study of gold producing firms with focus on the managerial views on corporate policies, that there is no evidence that shareholders benefit from selective hedging. The results of the study furthermore implicate: Selective hedging is a common practice within the sector of nonfinancial companies, but where firms are unlikely to have informational advantages, selective hedging is uncommon in a broader context.

This article deals with the use of hedging instruments (explicit reference to: forwards, swaps, options and futures) with a focus on Northern German SMEs with a account at Sparkasse Holstein.

\section{METHODOLOGY AND DATA}

The paper analyzes whether currency risk management is a common practice in Northern German SMEs with a bank account to Sparkasse Holstein. For this purpose, more than 58,000 foreign transactions were valued, analyzed and classified over a period of more than 1.5 years (March 2017 to September 2018). The study group with a bank account to Sparkasse Holstein consists of 821 companies with an annual turnover from approx. EUR 1 million up to

\footnotetext{
${ }^{1}$ The main reason of limited availability of empirical studies is data limitation. The German "Mittelstand" or so-called SMEs - faces strong competition in their market. It seems obvious, that they are not willing to give information on pricings and hedging activities. Only bank employees can research the real use of hedging in SMEs.
} 
approx. 48 million. In addition, each company employs fewer than 500 , but at least 8 people. These companies are clearly categorized as SMEs. To characterize the sample, a total of 236 companies have at least one foreign currency account, while an active currency management is explicitly used by 121 companies.

The USD, as the dominant foreign currency, represents most of the FX-accounts (211). The currencies GBP (102) and CHF (70) can be explained by their proximity to the European Monetary Union. Due to the regional reference of the bank to the Scandinavian countries, the examined SMEs also use for a great part DKK FX-accounts (30).

All in all, 236 companies with a foreign currency account have on average 1.3 foreign currency accounts at Sparkasse Holstein. The standard deviation is 0.81 . Hereby, the average distance to the mean is nearly one more foreign currency account per company. While the 121 companies with active currency management have an average annual turnover of approx. EUR 22 million, the study group had an average annual turnover of approx. EUR 9 million. The arithmetic mean of the transactions is approx. EUR 35,000, where the median is more precise due to many statistical outliers of EUR 19,000. The investigated companies were either too small to engage in foreign currency transactions with other banks or were asked before the investigation whether there was another bank account for FX-hedging activities. The exception were larger companies with another bank account, which share their FX-business in equal parts to both accounts. In principle the Sparkasse Holstein is the sole supplier in terms of foreign currency transactions or has at least half of FX-transactions (these are only companies that count among the 121 companies with an active currency management anyway).

The period from March 2017 to September 2018 was chosen to test the behavior of companies nearly ten years after the financial crisis back in 2009. Based on an analysis by Koh (2010) of the 32 most relevant foreign currencies in terms of volatility between 2005 and 2010, it became clear that in the years leading up to the global financial crisis in 2009, market volatility was much higher, than in the postcrisis period. It can be presumed that approx. ten years after the last crisis, nearly every company should be sufficiently informed and, following the increased volatility during and after the crises, almost every foreign currency position should be hedged - at least within the scope of SMEs, due to the higher risk of default. In this case the research question is, at what level they continue to hedge themselves. By nature, foreign transactions are only a small part of the total transactions that are not an integral part of the study.

To start with a standard approach, used by Jorion (1990), namely in Bali et al. (2007) and Jorge and Augusto (2016), the company's exposure to exchange rate movements can be measured by the volume of the number of transactions. With increasing volatility, foreign currency transactions with a long maturity must be hedged or covered directly at the time of closing. Only 121 companies use FX-hedging to reduce the risk arising from volatility. Tab. 1 shows the relation of volatility to volume and transactions, where transactions mainly arise from 700 companies involved in foreign business without an active currency management (Jorge and Augusto, 2016). The volatility of the top six currencies (within the scope of Sparkasse Holstein) is being illustrated, while the volume of every currency defines the rank within Tab. 1.

There is no doubt that hedging with the right strategy $^{2}$ will reduce the level of risk exposed to a company. Jorge and Augusto (2016) found in their study, that derivatives only increase risk, when they are used to take on advantage of given market imperfections.

Davies et al. (2006) focus on exporting companies that were exposed to currency risk. They found out that the use of currency management essentially avoids financial distress and is dependent on the size and liquidity of the company. Their results provide evidence, that

\footnotetext{
${ }^{2}$ The right hedging strategy depends on the risk preference of a market participant. Hedging the calculation price on the basis of which a foreign transaction is still profitable is risk averse, i.e. calculated break-even exchange rate 1.05 USD/EUR and a current exchange rate 1.10 USD/EUR. Hedging the whole transaction at 1.10 USD/EUR secures the profit, but excludes a further participation.
} 
$70 \%$ of Norwegian exporters hedge the FX-risks. It is necessary to examine, if this also applies to Northern German SMEs. Hypothesis $H_{1}: 70 \%$ of Northern German SMEs hedge against FXrisks.

In addition, it must be clarified hypothesis $\mathrm{H}_{2}$, whether the hedging activity depends on the knowledge of the company. McCarthy (2014) explores the motives behind hedging activities. He found out in his research that firms do not know hedging as an instrument to reduce the risk of foreign transactions. Companies might not understand the risk of currencies and the impact on the firm's performance. He found out, that companies think their foreign amount of money is too small to be concerned about.

Furthermore, the following hypotheses should be checked to identify further characteristics of the recent status of hedging within Northern German SMEs:

1. Hypothesis $H_{3}$ : With increasing foreign currency turnover as well as increasing number of transactions, the number of foreign currency accounts increases.

2. Hypothesis $H_{4}$ : As the amount of each transaction increases, the currency risk is hedged more often.

3. Hypothesis $H_{5}$ : The majority of SMEs use an active currency management to hedge against the FX-risk.
An analysis of foreign payment transactions of a Northern German medium-sized bank within the period from March 2017 to September 2018, led to dominant currencies being identified. In this case, only significant transactions ( $\geq$ EUR 10) in terms of FXhedging instruments like forwards, swaps, options and futures were counted. Following this restriction, marginal account settlements are not part of the study. The focus is on the total volume in EUR equivalent and the number of trades with the corresponding foreign currency. In the second step, only those transactions were considered that had a cumulative total volume of over 1.5 million EUR equivalent. Likewise, statistical outliers were excluded from the survey. These include one-off transactions in exotic currencies, such as South African Rand. As a result, only the six largest currencies, counted by transaction volume and number of transactions, were included in the valuation within the observed period. In the third step, the cumulated transactions per currency unit were examined regarding the historical price trend. The exchange rate fluctuations of the individual currencies were calculated by using the exchange rate history of the foreign exchange (finanzen.net, 2019) for the investigation period, using the average of daily differences for each currency between March 2017 and September 2018. ${ }^{3}$

\section{RESULTS}

Over the investigation period from March 2017 to September 2018 a total of only 1269 FXhedging activities were observed. The abovementioned method has resulted in a total of six currencies being identified as shown in Tab. 1 . The highest volatility in relation to the EUR was calculated for the USD, volume and number of transactions are also dominant here. Overall, more than 2,100 transactions with a weighted, by the number of transactions, average volatility of $w_{i}=10.35 \%$ were observed with a cumulative value of more than EUR 243 million.
Other transactions in other currencies were not paid attention to due to the methodological restrictions made above.

The correlation between the volatility of a currency, the converted volume and the number of transactions shows an overall positive correlation. This is a stylized fact.

However, the positive correlation between general hedging activities only allows conclusions to be drawn about those companies with active currency management but does not explain the entire corporate client base

\footnotetext{
${ }^{3}$ Presumption: Every company could have benefited from the lowest daily low or the highest daily high via a limit order: stop loss or take profit at a certain exchange rate.
} 
with foreign operations. This leads to the assumption (hypothesis) that all those companies without foreign exchange trading either have no knowledge of currency volatility (the perception of FX-risk is not given) or no hedging occurs due to uncertainties regarding a currency management. Under the premise that the traded foreign currency of the 121 companies with active FX-hedging is subject to foreign contracts: During the investigation period approx. 126 million EUR secured volume can be observed. On the other hand, there are 700 companies without active currency management. An observed volume of approx. EUR 964 million (EUR 741 million in foreign currency and around EUR 224 million in EUR currency). Thus, the statement can be made that $12 \%$ of the foreign contracts of the 121 companies are hedged with foreign exchange trading and $88 \%$ of the 700 companies are unsecured or not hedged.

Tab. 1: Currency volatility-matrix using historical data of finanzen.net (2019), added by volume and transactions

\begin{tabular}{ccccc}
\hline No. & Currency & $\begin{array}{c}\text { Volatility } \\
\text { [\%] }\end{array}$ & $\begin{array}{c}\text { Volume } \\
\text { [mil. EUR] }\end{array}$ & $\begin{array}{c}\text { Number of } \\
\text { transactions }\end{array}$ \\
\hline 1 & USD & 11.11 & 182.44 & 1,816 \\
2 & GBP & 4.77 & 32.82 & 154 \\
3 & CHF & 6.80 & 17.77 & 39 \\
4 & JPY & 10.34 & 4.40 & 45 \\
5 & DKK & 2.05 & 3.98 & 38 \\
6 & NZD & 6.17 & 1.67 & 14 \\
\hline Total & & & 243.08 & 2,106 \\
\hline
\end{tabular}

Tab. 2: Correlation of volatility, volume and transactions, using historical data of finanzen.net (2019)

\begin{tabular}{lccc}
\hline & Volatility & Volume & Transactions \\
\hline Volatility & 1 & & \\
Volume & 0.58 & 1 & \\
Transactions & 0.59 & 0.99 & 1 \\
\hline
\end{tabular}

The observed correlation between volatility and transactions can also be verified by the number of foreign currency accounts of those 821 companies with recurring transactions in foreign currencies. Within the scope of the study group 236 companies with at least one foreign currency account were identified, as shown in Tab. 3. It can be assumed that the number of foreign currency accounts should at least tend to rise as the number of transactions increases. ${ }^{4}$ The average volume of a foreign currency transaction makes it clear that those companies that have a foreign currency account mostly use it for larger transaction volumes. The weighted average of all foreign currency transactions (weighted by the number of transactions) shows that payments over EUR 40,000 and above are made through foreign currency accounts.

In general, the hypothesis that the number of foreign currency accounts tends to increase as the number of transactions increases can be confirmed by the regression, as shown in Fig. 1. The regression diagram shows a correlation between the two variables, but correlation is not equal to causality.

Tab. 3: Structure of companies with foreign currency accounts

\begin{tabular}{ccccc}
\hline $\begin{array}{c}\text { FX-accounts } \\
\text { per company }\end{array}$ & $\begin{array}{c}\text { Number of } \\
\text { companies }\end{array}$ & $\begin{array}{c}\text { Number of } \\
\text { transactions }\end{array}$ & $\begin{array}{c}\text { Average volume } \\
\text { of transactions }\end{array}$ & $\begin{array}{c}\text { Sum } \\
\text { [mil. EUR] }\end{array}$ \\
\hline 1 & 196 & 17,530 & 34,467 & 416.49 \\
2 & 22 & 4,224 & 63,441 & 169.81 \\
3 & 12 & 4,651 & 30,946 & 220.74 \\
4 & 1 & 117 & 41,571 & 2.14 \\
5 & 4 & 1,008 & 114,046 & 30.72 \\
6 & 0 & 0 & 0 & 0 \\
\hline Total & 1 & 549 & 4,150 & 6.41 \\
\hline
\end{tabular}

\footnotetext{
${ }^{4}$ This relationship is tested only on foreign-active companies within the study group, that already have at least one foreign-currency account.
} 


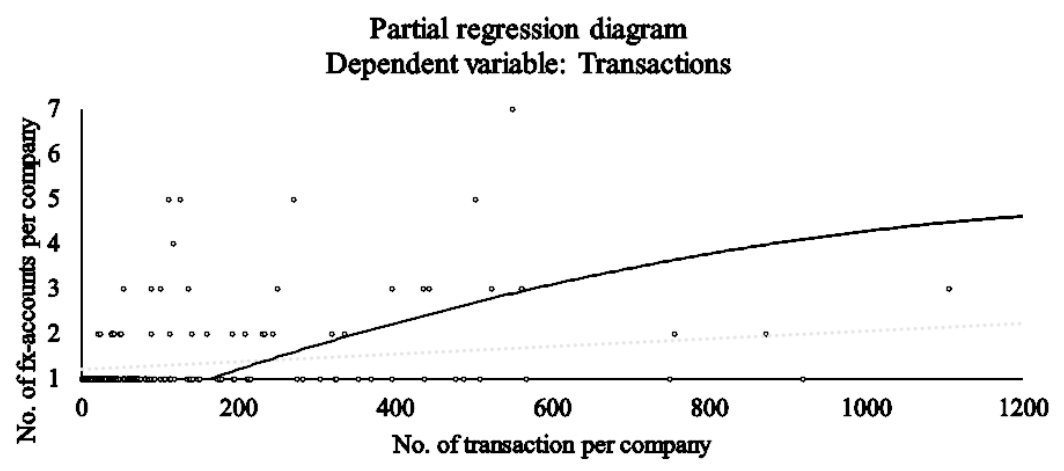

Fig. 1: Regression diagram of number of transactions and the number of FX-accounts.

The regression analysis in Tab. 4-6 shows that the coefficient of determination decreases with the inclusion of another variable (volume of transactions). This leads to the assumption that the transaction volume has only a small influence on the number of foreign currency accounts. Using the ANOVA matrix in Tab. 5, the explanatory contribution can be determined. Since the value of Significance $F$ is significantly below the value of $F$ statistic, an overall high contribution to explanation can be determined. The $P$-value of both $x$ variables is well below 0.05 . This indicates a positive impact of the $x$-variables on the $y$ variable. The transaction volume, measured by the coefficient, has only a very small positive influence on the number of foreign currency accounts. The coefficient of the number of transactions has a more positive impact. As transactions increase, the use of another foreign currency account increases by 0.000605 , with an intercept starting at 1.176426 .

Tab. 4: Regression statistics matrix of volume and number of transactions

\begin{tabular}{lc}
\hline Correlation Coefficient & 0.312420 \\
R Square & 0.097606 \\
Adjusted R Square & 0.089860 \\
Standard Error & 0.781363 \\
\hline Observations & 236 \\
\hline
\end{tabular}

The variables transaction volume, number of foreign currency accounts and number of transactions of those identified 236 companies with at least one foreign currency account were used in the correlation analysis shown in Tab. 7.

The transaction volume correlates with the number of transactions, as increasing sales tend not to be handled by a single transaction. The correlation between the number of FX-accounts and the transaction volume is $r=0.338$. This positive correlation coefficient indicates that there is a correlation of both variables in the same direction. According to Cohen (1992), this correlation corresponds to a medium effect. This means that higher transaction volumes also increase the number of foreign currency accounts. Furthermore, the number of FX-accounts correlates significantly with an increasing transaction volume per company $(r=0.338 ; n=236)$. The correlation can be explained by an omnipresent currency risk, because the exchange rate risk is not completely circumvented by a foreign currency account, but the conversion becomes an influenceable hedging instrument. While currencies that are converted by the bank at the current exchange rate as the payment arrives (STP - Straight Trough Processing) cannot be influenced (acceptance of the respective daily rate; no holding of the currency or early currency hedging at a fairly good rate). Much stronger, however, is the correlation between the number of $\mathrm{FX}$-accounts and the number of transactions $(r=0.432 ; n=236)$, as shown in Tab. 7. According to Cohen (1992), the correlation has a medium to strong severity. The number of FX-accounts correlates significantly with the number of transactions. The 
Tab. 5: ANOVA matrix of volume and number of transactions

\begin{tabular}{lrcccr}
\hline & df & Sum of squares & Mean square & F statistics & Significance F \\
\hline Regression & 2 & 15.386645 & 7.693322 & 12.601082 & 0.000006 \\
Residue & 233 & 142.253186 & 0.610529 & & \\
\hline Total & 235 & 157.64 & & & \\
\hline
\end{tabular}

Tab. 6: Intercept, Coefficients, T-Statistics and Standard Error matrix of volume and number of transactions

\begin{tabular}{lccrc}
\hline & Coefficients & Standard Error & T-Stat. & P-value \\
\hline Intercept & 1.176426 & 0.056898 & 20.676169 & 0.000000 \\
Volume of transactions & 0.000000 & 0.000000 & 2.685797 & 0.007756 \\
Number of transactions & 0.000605 & 0.000224 & 2.696348 & 0.007522 \\
\hline
\end{tabular}

Tab. 7: Spearman-Rho Correlation between FX-Accounts, Transaction volume and number of Transactions $(n=236)$. The correlation is significant at the 0.01 level (two-sided)

\begin{tabular}{llccc}
\hline & & $\begin{array}{c}\text { Number of } \\
\text { FX-accounts }\end{array}$ & $\begin{array}{c}\text { Transaction } \\
\text { volume }\end{array}$ & $\begin{array}{c}\text { Number of } \\
\text { transactions }\end{array}$ \\
\hline Number of FX-accounts & Correlation coefficient & 1.000 & 0.338 & 0.432 \\
& Sig. & & 0.000 & 0.000 \\
\multirow{2}{*}{ Transaction volume } & Correlation coefficient & 0.338 & 1.000 & 0.780 \\
& Sig. & 0.000 & & 0.000 \\
Number of transactions & Correlation coefficient & 0.432 & 0.780 & 1.000 \\
& Sig. & 0.000 & 0.000 & \\
\hline
\end{tabular}

more FX-accounts a company has, the more transactions will be reflected on these accounts. This indicates that as the number of FXaccounts increases, the awareness of currency risks within the scope of the companies also increases.

However, while foreign exchange trading and existing currency accounts of corporate customers are related to transactions and the number of foreign currency accounts, this dependency may not be common to all companies surveyed. A total of 821 companies with foreign currency activities were identified during the investigation period. The proportion of clients with foreign currency accounts is only $28.75 \%$ (236 companies), but only $14.74 \%$ (121 companies) of clients were identified, using hedging activities, such as forwards, swaps, options and futures. While not every company with a foreign currency account hedges, 85.26\% (700 companies) have no active currency management. Considering the individual transactions of SMEs, whether they were transferred from the EUR-account or from the foreign currency account, the transactions can be categorized and split as shown in Tab. 8.

The majority of foreign currency transactions were transferred from the EUR-account. In other words, about $66 \%$ of all foreign currency transactions are paid by the EUR-account. In contrast, only approx. $34 \%$ of all transactions settled at the expense to the foreign currency account.

This classified data set can be examined using the Chi-square test. From the observed record shown in Tab. 8, the question arises as to whether the choice of account type (EUR-account or FX-account) depends on the transaction volume. The $H_{0}$ hypothesis is: The choice of the account type is independent of the transaction volume. Whereas the $H_{1}$ hypothesis is: The choice of account type is not independent of the transaction volume.

Using the Chi-square in Tab. 9 and the degrees of freedom as conventional criteria, this entitles a difference as extremely statistically significant, due to a two-tailed $p$-value less than 0.0001 . That means, from a statistical point of 
Tab. 8: Comparison of transactions in terms of the EUR-account or FX-account classified by transfer amount (observed)

\begin{tabular}{|c|c|c|c|c|}
\hline \multirow{2}{*}{$\begin{array}{l}\text { Observed data } \\
\text { in EUR (categorized) }\end{array}$} & \multicolumn{2}{|c|}{ EUR-account } & \multicolumn{2}{|c|}{ FX-account } \\
\hline & Number & $(\%)$ & Number & $(\%)$ \\
\hline Less than 1,000 & 8,760 & $(64)$ & 1,122 & (16) \\
\hline Between 1,000 and 4,999 & 2,323 & $(17)$ & 1,804 & $(25)$ \\
\hline Between 5,000 and 9,999 & 815 & (6) & 1,116 & $(15)$ \\
\hline Between 10,000 and 49,999 & 1,407 & $(10)$ & 2,042 & $(28)$ \\
\hline Between 50,000 and 99,999 & 266 & $(2)$ & 610 & (8) \\
\hline Between 100,000 and 149,999 & 96 & (1) & 204 & (3) \\
\hline Over 150,000 & 71 & $(1)$ & 313 & $(4)$ \\
\hline Total of 20,949 transactions & 13,738 & $(100)$ & 7,211 & $(100)$ \\
\hline
\end{tabular}

Tab. 9: Comparison of transactions in terms of the EUR-account or FX-account classified by transfer amount (expected)

\begin{tabular}{lrrrr}
\hline Observed data & \multicolumn{2}{c}{ EUR-account } & \multicolumn{2}{c}{ FX-account } \\
in EUR (categorized) & Number & \multicolumn{1}{c}{$(\%)$} & Number & $(\%)$ \\
\hline Less than 1,000 & 6,480 & $(31)$ & 3,402 & $(16)$ \\
Between 1,000 and 4,999 & 2,706 & $(13)$ & 1,421 & $(7)$ \\
Between 5,000 and 9,999 & 1,266 & $(6)$ & 665 & $(3)$ \\
Between 10,000 and 49,999 & 2,262 & $(11)$ & 1,187 & $(6)$ \\
Between 50,000 and 99,999 & 574 & $(3)$ & 302 & $(1)$ \\
Between 100,000 and 149,999 & 197 & $(1)$ & 103 & $(1)$ \\
Over 150,000 & 252 & $(1)$ & 132 & $(1)$ \\
\hline Total of 20,949 transactions & 13,738 & $(100)$ & 7,211 & $(100)$ \\
\hline
\end{tabular}

view, the $H_{0}$ hypothesis is rejected. As a result, the choice of account is not independent of the transaction volume. This is particularly evident in the higher transaction volumes. With perfect accordance, the example of the "over 150,000" would be that significantly more transactions would run via the EUR-account (252 instead of 71 observed). Whereas most transactions (compare percentages behind the observed values and the expected ones) continue to be settled via the EUR-account. The hypothesis that most of the examined companies do not operate an active currency management cannot be rejected. If all companies carry out an active currency management, all transactions greater than 4,999 EUR should be settled via the FXaccount, to avoid an imminent currency risk.

In total, 700 companies that did not hedge the foreign exchange risk during the investigation period, were identified. It becomes clear that most companies transfer money to other
European countries with just one currency (around 68.1\%). Including companies transferring abroad with two currencies (i.e. EUR and USD), cumulated $89 \%$ of the investigation or cumulated 624 companies can already be explained, as shown in Tab. 10. If we now subtract all EUR-payments from the data set in Tab. 10, the parameters are quite different, as shown in Tab. 11.

After subtracting all EUR-payments into foreign countries in Tab. 11, it becomes clear that out of the originally 700 identified companies, only 367 use a foreign currency and thus explicitly wish to convert the EUR within their own bank to partly influence the conversion (no arbitrariness) - that equates to 52.4 percent of the SMEs using a (light) hedging strategy. ${ }^{5} \mathrm{On}$ the other hand, there are 333 companies $(700-$ $367)$ that only transfer to foreign countries in EUR. Nevertheless, it is more than questionable why a total of 700 companies do not use an

\footnotetext{
${ }^{5}$ This is not an active currency management. This type of currency hedging uses the company's known conversion margins to avoid foreign margins from other foreign banks.
} 
Tab. 10: Comparison of payments - number of currencies and countries

\begin{tabular}{|c|c|c|c|c|c|c|c|c|c|c|c|c|}
\hline & \multicolumn{2}{|r|}{1} & \multicolumn{2}{|r|}{2} & \multicolumn{2}{|r|}{3} & \multicolumn{2}{|r|}{4} & \multicolumn{2}{|r|}{5} & \multicolumn{2}{|r|}{ Sum } \\
\hline 1 & 375 & $(53.6 \%)$ & 65 & $(9.3 \%)$ & 14 & $(2.0 \%)$ & 9 & $(1.3 \%)$ & 14 & $(2.0 \%)$ & 477 & $(68.1 \%)$ \\
\hline 2 & 13 & $(1.9 \%)$ & 60 & $(8.6 \%)$ & 29 & $(4.1 \%)$ & 17 & $(2.4 \%)$ & 28 & $(4.0 \%)$ & 147 & $(21.0 \%)$ \\
\hline 3 & 0 & $(0.0 \%)$ & 3 & $(0.4 \%)$ & 15 & $(2.1 \%)$ & 11 & $(1.6 \%)$ & 19 & $(2.7 \%)$ & 48 & $(6.9 \%)$ \\
\hline 4 & 0 & $(0.0 \%)$ & 0 & $(0.0 \%)$ & 3 & $(0.4 \%)$ & 2 & $(0.3 \%)$ & 11 & $(1.6 \%)$ & 16 & $(2.3 \%)$ \\
\hline 5 & 1 & $(0.1 \%)$ & 0 & $(0.0 \%)$ & 0 & $(0.0 \%)$ & 0 & $(0.0 \%)$ & 11 & $(1.6 \%)$ & 12 & $(1.7 \%)$ \\
\hline Total & 389 & $(55.6 \%)$ & 128 & $(18.3 \%)$ & 61 & $(8.7 \%)$ & 39 & $(5.6 \%)$ & 83 & $(11.9 \%)$ & 700 & $(100.0 \%)$ \\
\hline
\end{tabular}

Tab. 11: Comparison of payments - number of currencies and countries, excl. EUR-currency-payments

\begin{tabular}{|c|c|c|c|c|c|c|c|c|c|c|c|c|}
\hline & \multicolumn{2}{|r|}{1} & \multicolumn{2}{|r|}{2} & \multicolumn{2}{|r|}{3} & \multicolumn{2}{|r|}{4} & \multicolumn{2}{|r|}{5} & \multicolumn{2}{|r|}{ Sum } \\
\hline 1 & 142 & $(38.7 \%)$ & 53 & $(14.4 \%)$ & 30 & $(8.2 \%)$ & 14 & $(3.8 \%)$ & 28 & $(7.6 \%)$ & 267 & $(72.8 \%)$ \\
\hline 2 & 2 & $(0.5 \%)$ & 17 & $(4.6 \%)$ & 13 & $(3.5 \%)$ & 14 & $(3.8 \%)$ & 20 & $(5.4 \%)$ & 66 & $(18.0 \%)$ \\
\hline 3 & 0 & $(0.0 \%)$ & 1 & $(0.3 \%)$ & 8 & $(2.2 \%)$ & 2 & $(0.5 \%)$ & 11 & $(3.0 \%)$ & 22 & $(6.0 \%)$ \\
\hline 4 & 0 & $(0.0 \%)$ & 0 & $(0.0 \%)$ & 0 & $(0.0 \%)$ & 0 & $(0.0 \%)$ & 11 & $(3.0 \%)$ & 11 & $(3.0 \%)$ \\
\hline 5 & 1 & $(0.3 \%)$ & 0 & $(0.0 \%)$ & 0 & $(0.0 \%)$ & 0 & $(0.0 \%)$ & 0 & $(0.0 \%)$ & 1 & $(0.3 \%)$ \\
\hline Total & 145 & $(39.5 \%)$ & 71 & $(19.3 \%)$ & 51 & $(13.9 \%)$ & 30 & $(8.2 \%)$ & 70 & $(19.1 \%)$ & 367 & $(100.0 \%)$ \\
\hline
\end{tabular}

active currency management, although foreign transactions are made. It is also interesting to note that 367 companies also transfer in one or more foreign currencies, even though they do not use hedging instruments like forwards, swaps, options and futures.

\section{DISCUSSION AND CONCLUSIONS}

Based on the positive correlation of the general hedging activities, it can be assumed that those companies with hedging activities have understood currency hedging as a relevant factor or have at least been adequately sensitized based on the expertise of an adviser ${ }^{6}$.

To draw a clear picture of German SMEs regarding their hedging behavior, ongoing research must pursue according to an empirical study of those who did not hedge in the past and congruently to this study did not hedge their currency risks within the scope of this research. In other words, an ongoing research on those who did not hedge must follow to completely understand the decision against hedging within SMEs.

In general, the hypothesis that as the number of transactions increases, the number of foreign currency accounts also tends to increase, was already tested back in 1997. According to Fok et al. (1997) diversified companies and smaller companies might already have low income and a lower volatility in terms of open foreign currency positions. The consequence is a lower need of hedging. On the other side MNEs tend to have higher foreign exchange risks and reveal a higher need of hedging. In this case the hypothesis has not been rejected, due to the regression analysis and correlation: A coefficient of determination of $18.66 \%$ indicates that both variables are determined by common sources of variance. Due to the medium to strong correlation, a connection can be assumed. The more FX-accounts a company has, the higher the overall number of transactions on these accounts., indicating: with increasing number of FX-accounts, predominates the awareness of currency risks. Although, based on the regression model, only a few of the observed values can be explained with a coefficient of deter-

${ }^{6}$ An "adviser" is a currency expert in a bank that advises the company on currency risks. 
mination $\left(R^{2}=0.0006\right)$, it also becomes clear that a significant increase in foreign currency accounts per company can only be expected, if a company has more than 200 transactions. This is partly due to the dominance of the USD, but also to the study group of the evaluated SMEs, as their focus is not solely on foreign countries.

On the other hand, a positive correlation between the number of FX-accounts and the transaction volume indicates that higher transaction volumes also increase the number of foreign currency accounts. However, it is common practice that as the volume of transactions increases, awareness of currency risks and demand for currency accounts also increases. This correlation is explained by an omnipresent currency risk. A company without a currency account needs to accept a given exchange rate, when for example transferring foreign currency from the EUR-account, while a company with a foreign currency account can hedge their needed amount of foreign currency or hold the foreign currency on the account until a better exchange rate is achieved.

The third hypothesis can only be partially substantiated by the regression. Due to incomplete information of the purpose for each transaction, it can only be shown that, as the number of foreign currency transactions per company increases, the number of foreign currency accounts per company is going to increase. While few companies have more than two FX-accounts, it can at least be observed that some companies have at least one other foreign currency account in addition to the dominant USD, which is also briefly demonstrated by the Tab. 8 and 9 .

The analysis of approx. 60,000 transactions during the investigation period shows that a significant proportion of the transactions continue to take place with the acceptance of the exchange rate risk. The data from Tab. 8 shows that far more transactions from EUR-accounts ${ }^{7}$ go abroad, compared to transfers from foreign currency accounts (13,738 transactions from EUR-account vs. 7,211 transactions from FXaccount). The Chi-square test has shown that the choice of the account (EUR-account or FXaccount) is not independent of the transaction volume. Nonetheless, comparing the observed and expected levels in Tab. 8 and 9, many companies continue to operate without an active currency management in the overall average transaction volume. This proves the second hypothesis that most of companies do not currently have an active currency management. If we also take the results of transfer volumes, classified according to hedging or non-hedging, into consideration, it becomes clear that the hypothesis according to Davies et al. (2006) applies in part also to Northern German SMEs and can be confirmed. Thus, the hedging activity increases with the size of the transaction volume. Davies et al. (2006) found out that FX-hedgers (firms) in Norway are statistically different due to significance level of $1 \%$ in tax, the underinvestment at $10 \%$ level, the risk aversion at 5\% level, the size sales and asset values at less than $10 \%$ levels, the internationalization at $1 \%$ level and the liquidity at less than $10 \%$. This leads to the argue that Norwegian export companies have more opportunities in growing, a lesser diversified shareholder base, are significantly larger, operating under more financial constraints (lower level of liquidity) and are more international, compared to Northern German SMEs. Those results confirm the traditional theories and determinants of FX-hedging for Norwegian firms. Based on the Norwegian study, although underlying significantly more parameters, a first tendency can be derived. On the other hand, we can observe in Tab. 8 that cumulated 433 transactions ( $\geq 50,000$ EUR) went abroad in EUR. In contrast, there are cumulated 1,127 transactions ( $\geq 50,000$ EUR) that went from a foreign currency account abroad. While it cannot be assumed that EUR will be needed abroad, the relation shows a clear ignorance or even speculative component in those companies that have transferred from the EUR account. However, this contradicts the fifth hypothesis that most SMEs run active currency management because of their foreign currency risks. The customer structure of the

\footnotetext{
${ }^{7}$ In this case the transaction of the foreign currency is made at the expense to the EUR-account instead of the FX-account.
} 
examined bank has no MNEs and allows conclusions on Northern German SMEs and their usage of an active currency management. While in Tab. 2 a correlation between the volatility and the number of transactions was found, which is a stylized fact, conclusions can be drawn on the fifth hypothesis. However, these are negated due to the observed structure of payments from Tab. 7. The fifth hypotheses can be rejected. Although the volatility of foreign currencies, as shown in Tab. 1, could be clearly demonstrated in the individual currency pairs, a not inconsiderable proportion of companies has no foreign currency account and thus no active currency management, although a foreign currency activity could be proven. On the other hand, Crespo Cuaresma et al. (2014) have found that volatility may not affect the demand for hedging as the potential losses of foreign exchange depreciation are more often underestimated by companies than during the financial crisis. Larger transactions are hedged more frequently (transactions $>150,000$ EUR) as shown in Tab. 8. 313 were executed by the FX-account, while only 71 were executed from the EUR-account. It is noticeable that smaller payments are often made at the expense of the EUR-account. Thus, payments below EUR 10,000 were made to approx. $75 \%$ by the EUR-account. Only $25 \%$ of these payments were handled by the foreign currency account. Basically, the larger the payment, the greater the likelihood of being transferred in foreign currency.

It is noteworthy that the share of transactions below the value of 1,000 EUR, which go abroad as a foreign currency at the expense of the EUR-account, is dominant with $64 \%$. Here it can be concluded that small bills in foreign currency usually run at the expense of the EURaccount. With increasing value, the number of overseas sales at the expense of the EURaccount decreases, but values between EUR 10,000 and EUR 50,000 with 10\% share are quite high, suggesting that those companies without currency trading will bill their accounts against the EUR-account. ${ }^{8}$ While larger transactions exceeding EUR 100,000 are rare to SMEs, it can be said that companies with foreign currency accounts have significantly more transactions exceeding EUR 100,000 (cumulated 167 transactions at the expense of the EUR-account and cumulated 517 at the expense of the foreign currency account), as shown in Tab. 8. This suggests that the willingness to manage currencies increases with the increase in value per transaction, which confirms the fourth hypothesis that as the amount of each transaction increases, the currency risk is also better perceived. This trend is also confirmed by the inclusion of transactions over EUR 50,000, as given in Tab. 8. A total of cumulated 1,127 transactions of companies were made at the expense of the foreign currency account. In contrast, cumulated 433 transactions are made at the expense of the EUR-account. This is congruent with McCarthy's observation: McCarthy's study shows that SMEs have limited understanding of hedging and sometimes no understanding of FX-risk, exposure or hedging. Some companies equated hedging as speculation - which is a major issue, because not hedging is speculation (McCarthy, 2014). More evidence for the fourth hypothesis is given by increasing volumes per transaction, because the share of payments charged to the EURaccount decreases in comparison to the foreign currency account. Given the example of Tab. 8, 313 transactions of the equivalent of EUR 150,000 are made at the expense to the foreign currency account. The EUR-account points out only 71 transactions. The same can be seen in the clusters between EUR 100,000 and EUR 149,999 and between EUR 50,000 and EUR 99,999 .

However, if we consider those companies without foreign exchange trading but with foreign transfers in EUR or a foreign currency, as shown in Tab. 10, it becomes clear that out of 700 identified companies approx. $89 \%$ (cumulated) transfer money in one or two currencies abroad. If we assume that only $20 \%$ of these companies have a regular foreign currency requirement, approx. 125 companies of the investigation group should conduct currency management.

\footnotetext{
${ }^{8}$ Congruent with the high number of companies without foreign exchange trading and transactions abroad.
} 
If we narrow down the scope of the investigation (Tab. 11), only those companies are evaluated, that transfer money abroad only in foreign currency (excl. EUR transfers). If we sum up the companies in terms of their use of currencies again, it becomes clear that with the use of two currencies approx. $90.8 \%$ (cumulated) of the sample can be declared (underlying a total of 367 companies). Consistently, we follow the argument that $20 \%$ of these companies have regular foreign currency requirements. Thus, about 73 companies of the investigation group should operate a currency management. However, a comparison of Tab. 10 and 11 also shows that out of 700 companies with a foreign currency reference, only 367 (SMEs hedged ratio: $52.4 \%$ ) operate an active currency management. This confirms the examination results from 1997, where also approx. half of the SMEs were not hedged: According to the study of Fok, Carroll and Chiou (1997) 80\% (201 firms) of the hedged firms were MNEs, while 52\% (70 firms) MNEs were not hedged, with a significant level at $1 \%$.

Thus, the statement, based on the clients of Sparkasse Holstein, can be made that SMEs in Northern Germany hedge only to approx. $52 \%$. The results differ from those of the Norwegian study by Davies et al. (2006). They observed that approx. $70 \%$ of export-oriented companies hedge. The first hypothesis must be rejected, as the North German SMEs (client base of Sparkasse Holstein) are significantly different in terms of currency hedging from the Norwegian SMEs. On the other hand, a general statement can be made by using the data of Fok et al. (1997), Hentschel and Kothari (2001), Davies et al. (2006) as well as the data in this research: Hedging takes place in $50-70 \%$ of all mediumsized companies, but only 40 percent of nonfinancial firms do not hold any FX-positions in their portfolio. Remembering the financial crisis back in 2008/2009, where the market crashed and the exchange rates where highly volatile, a statement is given under the comparison of lower risk before the financial crisis and after the crisis: The higher the volatility in the market, the higher the share of hedging companies. It remains to ask in further research, why at least $30 \%$ of medium-sized companies even in times of high volatility expose themselves to the currency risk. For this purpose, the 700 companies, shown in Tab. 10, are possible subjects to a survey to find out the reasons for the conscious/ unconscious acceptance of the currency risk.

As already stated in the discussion, the following statement applies in principle: the larger the payment, the greater the likelihood of transferring in foreign currency. In addition, it has also been observed that payments smaller than EUR 10,000 are paid more frequently $(75 \%)$ from the EUR-account. It can be deduced that those companies without an FXaccount with at least two foreign currency transactions in the previous year are potential users of a foreign currency account.

To give an example: With an open bill of USD 14,000 and an assumed todays exchange rate of 1.14 USD/EUR, the equivalent is EUR 10,000. Over the course of time (term of payment, 6 months), the observed volatility of $11 \%$, as shown in Tab. 1, may result in an exchange rate change to 1.0146 USD/EUR. Consequently, the same invoice can be paid after 6 months to an equivalent of approx. EUR 13,800. In fact, it is also possible that the exchange rate is developing positively (i.e. 1.2 USD/EUR). Participating on this development, companies should also use active currency management and/or use options where the buyer has the right, but not the obligation, to converge at a certain strike price (Lacina and Toman, 2011). The cost driver "exchange rate changes" is not negligible. For SMEs, active currency management should be indispensable. That was also the conclusion of Ciner (2006). He concluded within the scope of his research, that hedging is more important than speculation as the main motive of trading. This statement also applies after the financial crisis in 2009. Whenever it comes to foreign exchange rates, one currency appreciates and the other depreciates. Riederová (2011) argues, two years after the financial crisis, in her study of the EUR/CZK currency pair, that a suitable hedging strategy for importers and exporters should be mandatory to minimize or even eliminate currency risks.

To sensitize SMEs, a bank should offer a foreign currency account at attractive terms, 
so that the currency risk can be minimized. If the exchange rate is hedged early and the issuer collects exchange gains, while waiving monthly fees until the company hedges frequently, this corresponds to a win-win situation. Billing in foreign currency is particularly attractive for companies with an import or export share because the foreign business partner is not exposed to any exchange rate risks. As a result, the company generates a competitive advantage. Once the company hedges exchange rates through hedging, billing in foreign currency seems particularly attractive due to the fixed exchange rate per underlying transaction, as Fidrmuc et al. (2013) had already determined for Central and Eastern Europe.

An alternative is the introduction to the topic of active currency management. The identification of companies with recurring foreign transactions is essential. One starting point here is the average equivalent value of foreign transactions per company. Including the values from Tab. 1, each company can thus be shown which specific risks arise from their transactions.

\section{ACKNOWLEDGEMENTS}

This paper was created with the support of Sparkasse Holstein. I am grateful to Michael Semmler for the provision of the used data.

\section{REFERENCES}

Andrade, G. and Kaplan, S. N. 1998. How Costly is Financial (Not Economic) Distress? Evidence from Highly Leveraged Transactions that Became Distressed. The American Finance Association, 53 (5), 1443-1493.

Bali, T. G., Hume, S. R. and Martell, T. F. 2007. A New Look at Hedging with Derivatives: Will Firms Reduce Market Risk Exposure? Journal of Futures Markets, 27 (11), 1053-1083.

Bhaird, C. M. and Lucey, B. M. 2010. Determinants of Capital Structure in Irish SMEs. Small Business Economics, 35 (3), 357-375.

Brown, G. W., Crabb, P.є,R. and Haushalter, G. D. 2006. Are Firms Successful at Selective Hedging? The Journal of Business, 79 (6), 2925-2949.

Ciner, C. 2006. Hedging or Speculation in Derivative Markets: The Case of Energy Futures Contracts. Applied Financial Economics Letters, 2 (3), 189-192.

Cohen, J. 1992. Statistical Power Analysis. Current Directions in Psychological Science, 1 (3), 98-101.

Crespo Cuaresma, J., Fidrmuc, J. and Hake, M. 2014. Demand and Supply Drivers of Foreign Currency Loans in CEECs: A Meta-Analysis. Economic Systems, 38 (1), 26-42.

Davies, D., Eckberg, C. and Marshall, A. 2006. The Determinants of Norwegian Exporters' Foreign Exchange Risk Management. The European Journal of Finance, 12 (3), 217-240.
Deltuvaité, V., Kapounek, S. and Koráb, P. 2019. Impact of Behavioural Attention on the Households' Foreign Currency Savings as a Response to the External Macroeconomic Shocks. Prague Economic Papers, 28 (2), 155-177.

Fidrmuc, J., Hake, M. and Stix, H. 2013. Households' Foreign Currency Borrowing in Central and Eastern Europe. Journal of Banking \& Finance, 37 (6), 1880-1897.

finanzen.net. 2019. Exchange Rate History [online]. Available at: https://www.finanzen.net/devisen/ dollarkurs/historisch (USD), https://www . finanzen.net/devisen/pfundkurs/historisch (GBP), https://www.finanzen.net/devisen/ euro-schweizer_franken-kurs/historisch (CHF), https://www.finanzen.net/ devisen/euro-yen-kurs/historisch (JPY), https://www.finanzen.net/devisen/ euro-daenische_krone-kurs/historisch (DKK), https://www.finanzen.net/devisen/ euro-neuseeland_dollar-kurs/historisch (NZD). [All accessed 2019, May 08].

Fok, R. C. W., Carroll, C. and Chiou, M. C. 1997. Determinants of Corporate Hedging and Derivatives. A Revisit. Journal of Economics and Business, 49 (6), 569-585.

Frank, M. Z. and Goyal, V. K. 2009. Capital Structure Decisions: Which Factors Are Reliably Important? Financial Management Association International, 38 (1), 1-37. 
Hentschel, L. and Kothari, S. P. 2001. Are Corporations Reducing or Taking Risks with Derivatives? The Journal of Financial and Quantitative Analysis, 36 (1), 93-118.

Jorge, M. J. and Augusto, M. G. 2016. Is Hedging Successful at Reducing Financial Risk Exposure? Applied Economics, 48 (39), 3695-3713.

Jorion, P. 1990. The Exchange-Rate Exposure of U.S. Multinationals. The Journal of Business, 63 (3), 331-345.

Keasey, L. and Watson, R. 1993. The Bank Financing of Small Firms in UK: Issues and Evidence. Small Business Economics, 6 (1), 349-362.

KoH, K. H. 2010. Currencies' Exchange Rate Trend-Before and After Financial Crisis [online]. Massachusetts: Massachusetts Institute of Technology. Available at: https://dspace.mit.edu/handle/1721.1/59301. [Accessed 2019, May 08].

KulA, V. 2012. Foreign Exchange Exposure Perception and Management of Turkish SMEs. Journal of Small Business \& Entrepreneurship, 18 (4), 437-452.
Lacina, L. and Toman, P. 2011. A Free-Floating Currency Regime During Economic Crisis: Advantage or Disadvantage? Acta Universitatis Agriculturae et Silviculturae Mendelianae Brunensis, 59 (2), 165-176.

Malindretos, J. and Tsanacas, D. 1995. Hedging Preferences and Foreign Exchange Exposure Management. Multinational Business Review, $3(2), 56-66$.

McCarthy, S. 2014. Foreign Exchange Transaction Exposure Management Practices of Australian SMEs: An Exploratory Analysis. Small Enterprise Research, 7 (2), 29-42.

Papaionnnou, M. G. 2006. Exchange Rate Risk Measurement and Management. Issues and Approaches for Firms. IMF Working Papers, 06/255.

Quintiliani, A. 2018. Expected Cost of Financial Distress in Small and Medium-Sized Enterprises (SMEs): A German-Italian Comparison. African Journal of Business Management, 12 (1), 21-33.

Riederová, S. 2011. Currency Hedging with Help of Derivatives. Acta Universitatis Agriculturae et Silviculturae Mendelianae Brunensis, 59 (4), $273-280$.

\section{AUTHOR'S ADDRESS}

Jan Christoph Neumann, Department of Economics, Faculty of Business and Economics, Mendel University in Brno, Zemědělská 1, 61300 Brno, Czech Republic, e-mail: xneuman6@mendelu.cz,neumann.sbta@gmail.com 